\title{
Towards Formulating An Accounting Theory Of Meaningfulness
}

S. Wedzerai Musvoto, North West University, South Africa

Daan G. Gouws, University of Pretoria, South Africa

\begin{abstract}
This study highlights the need for a theory of meaningfulness for accounting information. A theory of meaningfulness determines the theoretical position that may be taken about the scientific content of information. The need for such a theory in accounting arises from the perspective that users of accounting information have not been able to take a firm theoretical position about the scientific content of accounting information in the financial statements. This has caused users of accounting information to lose confidence in the financial statements. This paper uses the representational measurement concept of meaningfulness to highlight the inadequacies of the current accounting concept of meaningfulness and to suggest possible ways of addressing these inadequacies. The development of a theory of meaningfulness of accounting information would improve the users' confidence in the financial statements.
\end{abstract}

Keywords: Meaningfulness Problem in Accounting; Accounting Theory; Measurement Theory; Typologies of Scales

\section{INTRODUCTION}

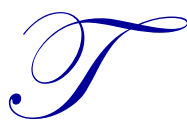

he key concept in this study is the description of the meaning of accounting information. Such a description would provide background and fundamental concepts to the development of a theory of meaning in the discipline.

The theory of meaning is rooted in the concept of measurement. According to Luce et al (1990) all processes of measurement must have criteria for determining the meaningfulness of the information produced. This suggests that all measurement information is considered to be meaningful information. The concept of seeking criteria to determine the usefulness of measurement information is known as the meaningfulness problem in measurement theory. Narens (2002) adds to this view by pointing out that the concept of information meaningfulness describes a theoretical position about scientific content and its role in inference. This means that a theory of meaningfulness describes the inferences that may be drawn from measurement information without distorting the meaning of the measure. If this is the case, it follows that measurement information can only be meaningful if the nature of valid inferences that may be drawn from the information are specified.

Several sources in accounting literature (see, IASB, 2009; Wolk et al, 2002) highlight that accounting is a measurement discipline. If this is the case, then a user of accounting information would expect to find an outline of the valid inferences that may be drawn from accounting information. Furthermore, such an outline of the valid inferences should be supported by a clear description of a theory of the meaningfulness of accounting information. However, studies by authors such as Evans (2003); Francis and Schipper, (1999); Lev and Zarowin, (1999); Sterling, (1997) highlight that users of accounting information have not been able to draw valid inferences from accounting information and as a result have sought alternative sources of financial information. This indicates that users of accounting information have not been able to take a firm theoretical position about the scientific content of accounting information in the financial statements. Hence, this also suggests that the financial statements do not have a clear description of a theory of the meaningfulness of accounting information. Since, it has been highlighted that all measurement information must be meaningful information this viewpoint also weakens the accounting discipline's position as a measurement discipline. 
In the light of the discussion above, the purpose of this study is to find out the shortcomings in the accounting theory of meaningfulness and to prescribe solutions to them. This would enable users to take a firm theoretical position about the scientific content of accounting information in the financial statements thereby increasing their confidence in the financial statements.

This study commences with a discussion of the research problem, purpose of the research and the research methodology in Section 2 and its subsections. This is followed by a brief discussion of the concept of meaningfulness in Section 3 followed by a discussion of the relationship between meaningfulness and the typologies of scales in Section 3 and its subsections. Section 4 review accounting literature with respect to its meaningfulness while, Section 5 examines the relationship between meaningfulness and the logic of hypothesis testing and, Section 6 concludes the study

\section{RESEARCH PROBLEM}

The problem being addressed in this study concerns the inability of users of accounting information to take a firm theoretical position about the scientific of content of information contained in the financial statements.

\section{Purpose}

The purpose of this study is to highlight the shortcomings of the accounting concept of meaningfulness from the representational measurement perspective and to suggest ways of addressing the problems.

\section{Critical literature analysis}

For over the past fifty years research and scholarship in accounting and management has focused on providing insights and advanced understanding of the usefulness of accounting information. According to Kaplan (2011) much of this scholarship has focused on how information and markets interact, including the information content of numbers. This means that accounting scholarship and research is interested in the use to which accounting information may be put by users. In measurement theory, the usefulness of information is determined by the concept of the meaningfulness of information. Since, accounting is considered to be a measurement discipline (see, IASB, 2010; Wolk et al, 2002), it follows that accounting information is bound by the representational measurement concept of meaningfulness. As noted in Section 1 for long accounting research and scholarship (see, Agoglia et al, 2011; Evans, 2003; Francis and Schipper, 1999; Lev and Zarowin, 1999; Sterling, 1997) have noted that users have not been able to take a firm theoretical position on the scientific content of the information contained in the financial statements. That is to say users are not able to make inference that can be described in a dichotomous manner. This makes their inferences drawn from accounting information vague and ambiguous.

Some earlier studies by authors such as Zebda (1991), Fellner (1961), and Franke (1978), have noted that ambiguity and vagueness exist in many accounting and auditing decisions. This suggests that it has been noted that for long users of accounting information have not been able take a firm theoretical position on the scientific content of the information contained in the financial statements. From the representational perspective, Luce et al (1990) point out that information can only be described as measurement information if it has the quality of meaningfulness that is described in unambiguous terms. If this is the case then, this implies that the concept of the meaningfulness of accounting information has not been adequately addressed. Hence, it may be argued that accounting might not be a true measurement discipline after all.

\section{The concept of meaningfulness}

The principles of modern measurement theory are synonymous with the representational theory of measurement. The representational theory of measurement originated in the social sciences with the work of Scott and Suppes, (1958). Since then, it has developed through the works of Luce et al, (1971, 1989, 1990), and Narens (2002) into a yardstick of measurement in social scientific disciplines. In tandem with the development of the representational theory has been the move towards the view of the process of measurement as an information process. This viewpoint became central to the development of theories of meaningfulness in measurement. 
According to Narens (2002:746) “...the only meaningful forms of measurement are equivalent to the representational theory; i.e., each meaningful set of measuring functions on a qualitative domain $A$ has a characterization as a set of structure preserving mappings from a qualitative structure with domain A into a purely mathematical structure". This definition highlights the in tandem development of the informational view of measurement with the representational form of measurement theory. It is also clear that these two perspectives are viewed as forming the basis for the study of qualitative aspects of measurement information. The implications of this view on a social scientific discipline such as accounting is that all its numerical assignments must comply with the principles of representation for the information it produces to be useful. Furthermore, given that the IASB (2009) points out that accounting information must be produced in such a way that is useful to users it follows that it is imperative that accounting principles must comply with the principles of representational measurement.

The current approach to meaningfulness in measurement originated with Stevens' typologies of scales. This approach to meaningfulness makes it is essential to proscribe operations that use scales that do not fit in the process of representational measurement. Advocates of this approach consider meaningfulness to be absolute. For example, Townsend and Ashby (1984:394) state: "As is perhaps obvious, meaningfulness is an all or none concept. Thus, a statement cannot be almost meaningful". In measurement, it is clear that information is restricted to provably meaningful statements. It follows that measurement does not proceed by making statements that are inevitably in error or by formulating that are expected to be incorrect and then trying to do better. As Luce et al (1990:325) notes:

Actual measurement of such a pre-theoretical variable may come from a rather simple theory such as additive conjoint structure or from something more complex; or the hypothetical variable may dissolve into many related concepts as the theory develops. The use of physical indices for such pre-theoretical may be a useful initial step toward such a theory, but it must not be confused with the fundamental measurement of the variables.

It is clear that the debate of meaning in measurement reverts to the mathematics of measurement theory. That is, an individual has to know the attributes they wish to measure, the questions they wish to ask about the attribute, and that the numerical assignments made to these attributes preserves the peculiar features and relations among the attributes. When this happens, it means that measurements have been made on one of the recognized scales (i.e., Nominal, Ordinal, Interval, and Ratio). It follows that mappings of the information other than those permissible on the scale of measurement used would destroy the meaning of the information. As a result, operations to map the information should be selected from those that are permissible on the scale. With respect to the accounting discipline, it follows that accounting information has to be measured on one of the recognized scales (i.e., Nominal, Ordinal, Interval, and Ratio). This means that accounting information must specify the relationship between the empirical relational structure and the abstract structure for the information to be considered measurement information. The IASB (2009) points out that the attributes that are essential to measure in the preparation of the financial statements are cost and value. The literature further reiterates that monetary units must be used as the abstract structure of choice in measuring these attributes. This implies that the scales of measurement in accounting can only be specified in terms of the relationship between monetary units and cost or value. Therefore, it can be concluded that for accounting information to be meaningful, it is necessary to specify the scales used to measure cost or value.

\section{MEANINGFULNESS AND TYPOLOGIES OF SCALES}

The concept of a scale views the meaningfulness of statements about data for different scales as preserved under permissible transformations. According to Luce et al (1990) the essence of meaningfulness is embodied in the description of scale type and permissible statistics. This means that the soul of meaningfulness is personified by the description of the type of scale used and the statistics permissible on the scale. The tying of the concept of meaningfulness to the concept of a scale began with Stevens (1946)'s theory of scales of measurement. He presented the hierarchy of data scales based on the invariance of their meaning under different classes of transformations. According to this theory, scales that preserve meaning under a wide variety of transformations convey less information than those whose meaning is preserved by only a restricted class of transformations. For example, using the description of ordinal scale measurement given by Luce et al. (1971), deductions of expressions of the representation and uniqueness theorems on ordinal scale measurements are made to show that the structure of these scales can only be preserved under monotonic transformations. This deduction is given below: 
To show an expression of the representation theorem, assume that a scale, $b$, is used to assign real numbers in a set of real numbers $\mathrm{N}$ to the elements of a set, $\mathrm{S}$, of observed phenomena and it is required that the numbers be assigned so that for all $k$ and $m$ in $\mathrm{S}, \mathrm{b}(k)>\mathrm{b}(m)$ if and only if $k$ is preferred to $m$. Therefore, it follows from this that,

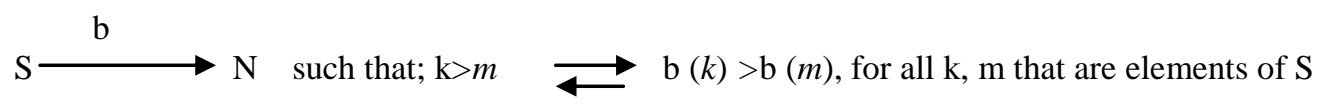

This expression shows the process of measurement in which an empirical relational structure $\mathrm{S}$ is represented by a numerical relational structure $\mathrm{N}$. The relation $\mathrm{k}>\mathrm{m}$ in $\mathrm{S}$ is preserved by the transformation (scale $\mathrm{b}$ ) that mapped it onto $\mathrm{N}$. The representation of the relation $\mathrm{k}>\mathrm{m}$ in $\mathrm{S}$ is given by $\mathrm{b}(\mathrm{k})>\mathrm{b}(\mathrm{m})$ in $\mathrm{N}$. This shows ordinal scale measurement.

When drawing inferences from measurement information it is necessary to understand the type of inferences that may be drawn. The inferences drawn should preserve the structure of the empirical relational system represented by the ordinal mapping. Stevens (1951:25) used the term permissible statistics to describe the type of statistical analyses that preserve the ordinality of the mapping shown above. Therefore, the expression of the uniqueness theorem for an ordinal scale measurement is proved if there is a transformation $f$ that is permissible for an ordinal scale if and only if:

$\mathrm{b}(\mathrm{k})>\mathrm{b}(\mathrm{m}) \longrightarrow f[\mathrm{~b}(\mathrm{k})]>f[\mathrm{~b}(\mathrm{~m})]$

This analysis indicates that ordinal scale data is invariant under all transformations that preserve order. According to Stevens (1951), the ordinal scale has a structure of what is called an isotonic or order preserving group. $\mathrm{He}$ asserts that this group is very large and includes all monotonic increasing functions, i.e. functions that never decrease and therefore do not have maxima. This reasoning reveals that the positive values on an ordinal scale may be replaced by their square or their logarithm or to perform a linear transformation, adding a constant or multiplying by another constant. With respect to the application of the ordinal scale in accounting, Musvoto (2008) notes that the classification of current assets or current liabilities in increasing or decreasing order of liquidity in the balance sheet implies the use of the ordinal scale. That is, the order among current assets or current liabilities in the balance sheet is defined by their liquidity. Therefore, if statistical analyses are carried out to obtain information on the order indicated by the liquidity relationship among current assets or current liabilities in the balance sheet; such analyses can only make sense if they provide information that is consistent with the order relationship that is defined by their liquidity. It follows that information can only be described as meaningful in relation to the relationship of liquidity among current assets in the balance sheet if it describes that relationship.

Similar arguments can also be developed for the interval scale. In order to develop an expression for the uniqueness theorem for the interval scale, the order (>) operator is replaced by the difference (-) operator. It follows that a transformation $\mathrm{f}$ is permissible for interval scale values if and only if there is a constant $\mathrm{c}$ such that: $\mathrm{b}(k)-\mathrm{b}$ $(m)=\mathrm{c}\{\mathrm{f}[\mathrm{b}(k)]-\mathrm{f}[\mathrm{b}(m)]\}$. It follows that linear transformations in which the same constant is added to each value or the multiplication of each value by a constant are permissible for interval scales (Stevens, 1951:25). Consequently, the statistics that are permissible in addition to those on the ordinal scale are the mean, standard deviation, order correlation and product moment correlation. With respect to the use of interval scales in accounting Musvoto (2008) explains that the interval scale is used in the accounting discipline in the measurement of monetary units. He points out that monetary units are placed at equal intervals, so that they can be counted to give the total amount of monetary units paid to acquire a commodity, or the total amount assigned to an element of the financial statements during recognition. Consideration was given an item costing ten dollars that is paid for using one-dollar bills and Musvoto (2008) states: "In order to get ten dollars it is necessary to count out ten one-dollar bills. It is important that the one-dollar bills are of equal worth so that ten of them can be counted to the get ten dollars needed to purchase the item. But if someone-dollar bills are worth much more than others, then perhaps fewer one-dollar bills need be counted to get to ten dollars. Therefore, the interval of worthiness cannot be considered to be equal among the one-dollar bills counted to give ten dollars. For an interval scale to hold, it is necessary that successive items in a relationship be at equal intervals in terms of that relationship. Meaningful statistical analyses about the ten dollars paid for the item are those that indicate that the one-dollar bills counted to get to ten dollars were of equal 
worthiness". Therefore, it follows that meaningful measurement information is that which tells the truth about the object it is describing.

With respect to the ratio scale Luce et al. (1971:10) assert that ratio it preserve relative ratios. This indicates that ratio scales have a defined zero point which may not be changed. Consequently, it is possible to multiply ratio scale data by a constant but logs may not be taken nor may a constant be added. Therefore, to develop an expression for the uniqueness theorem for the ratio scale, it follows from this that the permissible transformations on the ratio scale satisfy: $\mathrm{b}(k) / \mathrm{b}(m)=\mathrm{c} \mathrm{f}[\mathrm{b}(k)] / \mathrm{f}[\mathrm{b}(m)]$ for some constant $\mathrm{c}$. The statistics that are permissible on a ratio scale in addition to those of the nominal, ordinal and the interval scale are the geometric mean, coefficient of variation and decibel transformations.

In relation to ratio scale measurement in accounting Musvoto (2008) argues that ratio scales are used in the measurement of monetary units and that ratio scale measurements are measurements on the extensive scale. That is to say ratio scales have the same properties as natural numbers. This suggests that monetary units also have the same properties as the natural numbers. In the paragraph above all kinds of statistical analyses that can be carried out on ratio scale measurements were listed. It follows that all kinds of kinds of statistical analysis may be carried out on measures of monetary units.

Nominal scales are at the bottom of the hierarchy. They do not require numerical assignments, but rather unique identifiers. It follows from this that they are invariant under transformations that preserve the relationship between the identifiers and the objects they represent. Therefore, it is permissible to perform on the values, operations that do not combine or confuse identifies.

\section{Meaningfulness and permissible statistics}

In Section 3 it was noted that the study of meaningfulness in measurement theory examines the relationship between the objects represented and the symbols used to represent them. That is, the study of meaningfulness is equivalent to the study of the properties of a scale of measurement. Stevens' $(1946,1951)$ original development of ideas of meaningfulness and invariance are closely tied to the question of appropriate and permissible statistics. He argues that measurement information is meaningful under a set of permissible statistics that leave the scale invariant. This claim suggests that permissible statistics are those statistical analyses that accurately reflect the properties of the object the measurement information wishes to represent. It follows that measurement information is meaningful when the statistical interpretations made of it do not change the phenomena that the information purports to represent. It can also be inferred that it is necessary to know in advance the type of statistical analyses that leave the scale of measurement used in producing measurement information invariant. If this is the case, it can also be inferred that the statements that define the meaning of measurement information should be specified with the information.

In the accounting discipline, authors such as Chambers (1997), Willet (1987), Staubus (2004) and Ryan et al. (2002) assert that the scale of measurement between value and monetary units is not specified. This means that the relationship between monetary units and value is not known. In Section 2 it was highlighted that the specification of the scale of measurement is necessary for the establishment of the meaningfulness of measurement information. In other words, the meaningfulness of accounting information that describes the relationship between monetary units and value cannot be established. Therefore, the type of statistical analysis that may be applied to accounting information that describes the relationship between monetary units and value in order to draw accurate meaning about value cannot be specified. This creates a proliferation of statistical analyses that may be carried out on information about monetary units and value.

According to Luce et al. (1990:294) the link between meaningfulness and statistics is obvious. They argue that statistical calculations involve various numerical functions $\mathrm{f}(\mathrm{x} 1 \ldots \mathrm{xk})$, such as the arithmetic mean or the standard deviation, for a set of measurements (e.g., x1.,..., xk), and as a result it seems reasonable to require that the numerical relations defined by such functions be meaningful relative to the underlying empirical structure. This demonstrates that statistical analysis of measurement information that is meaningful is equivalent to the mapping of measurement information onto an abstract structure, while preserving the structure of the phenomenon that is 
represented by the measurement information. It also follows that statistical analyses on measurement information should be meaningful relative to the underlying empirical structure. It can therefore be concluded that the term meaningfulness is used to capture the idea that information may have little, or a great deal of, meaning in the sense that it conveys knowledge about an object or state of affairs.

Stevens' $(1951 ; 1946)$ typology of scales suggest that the determination of the meaningfulness of measurement information requires the specification of the scale used in measurement and the establishment of the statistical analyses that leave the scale invariant. Under Stevens' typology of scale, scale types are evident from the data, independent of the questions asked of the data. In Section 3 it was indicated that scale types can be nominal, ordinal, interval or ratio scales, and that these scales are arranged in a hierarchy. The lowest ranking scale is the nominal, followed by the ordinal and the interval with the top of the hierarchy being the ratio scale. The properties of lower ranking scales are incorporated in the higher-ranking scales. The meaningfulness of lower-ranking scales and permissible statistics on lower-ranking scales are incorporated into the higher-ranking scales. Therefore, it can be inferred from this that the meaningfulness of information increases in direct proportion to the increase in the permissible statistics, with the nominal scale being the least meaningful scale followed by the ordinal, interval and the ratio scale, which is the most meaningful. The following identity can be formulated: Let $\mathbf{M}$ be the meaningfulness of information, and let $\mathbf{S}$ be the permissible statistics, then $\mathbf{M}=\mathrm{kS}$, where $\mathrm{k}$ is a constant. Figure .1 below illustrates this relationship.

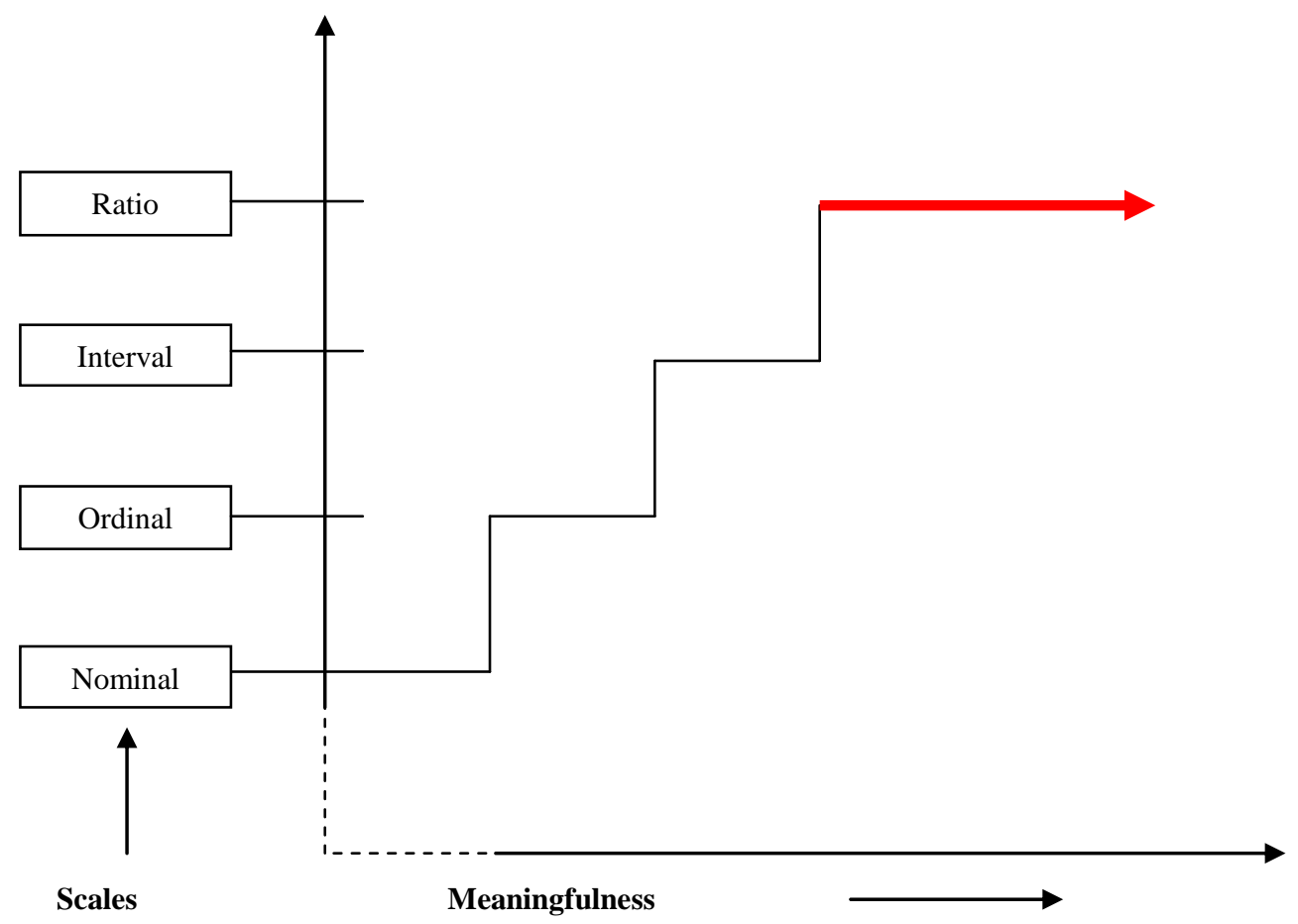

Figure.1 Stevens' scales of measurement against the concept of meaningfulness Source: Own Observation

Figure.1 illustrates the relationship between the permissible statistics and the meaningfulness of information. The distinguishing feature of this graph is that it reflects a step function. The most peculiar feature of the concept of meaningfulness is that, within the limits of a specified scale, meaningfulness does not change unless a new scale is introduced. It also reflects that either permissible statistics are defined within a specific scale or they are not. The graph also shows the hierarchy of scales. It indicates that lower ranking are incorporated in higher-ranking scales. The meaningfulness of lower-ranking scales is incorporated in high-ranking scales. It is also clear from the graph that defining a high-ranking scale automatically implies the definition of lower-ranking scales. Furthermore, 
since it has been outlined in Section 2 that meaningfulness is an all or nothing concept, the graph has an arbitrary starting point on both axes because it is not clear exactly what transpires before the nominal scale initially establishes meaningfulness.

\section{ACCOUNTING AND THE CONCEPT OF MEASUREMENT THROUGH MEANINGFULNESS}

In Section 2 it has been pointed out that compliance with the principles of representational measurement is critical for the production of meaningful in formation. This means that it is crucial for accounting practices and principles to be in harmony with the principles of representational measurement if meaningful information is to be produced by accounting processes. However, accounting practices have not been in compliance with the principles of representational measurement. This non- compliance could be sighted as the reason the usefulness of accounting information is questionable (see, Evans 2003; Francis and Schipper, 1999; Lev and Zarowin, 1999; Sterling, 1997). For example, Vickrey (1970) notices that the accounting discipline lacks a theory of measurement due to the absence of a specified additive attribute. An additive attribute would lead to a ratio scale measurement in accounting. If this attribute were present it would lead to the production of accounting information that is meaningful on the ratio scale. Furthermore ratio scale measurement uses the realist's perspective of measurement. According to Michell, (1995) the realist's theory of measurement advocates that measurements should reflect the empirical properties of the object they are representing. This means that quantifications in accounting would reflect the intrinsic properties of the accounting attribute being measured. It is important to note that both cost and value that are sighted in the accounting literature (IASB, 2009) as the attributes of the financial statements to be measured are not additive properties, and as a result they are not measurable on the ratio scale. The only aspect that is measurable on a ratio scale in accounting is the numerosity of monetary units (Musvoto, 2008). This means that inference about the meaningfulness of accounting information can only be made on the ratio scale level of measuring the numerosity of monetary units. It is important to note that meaningful inference cannot be drawn about either cost or value from the measurements of the numerosity of monetary units.

Chambers (1997) also notes the lack of meaningfulness of accounting information when he refers to the lack of a scale of measurement and the lack of specified attributes of measurement. In Section 2 it was noted that in the representational context information is meaningful once a scale of measurement is specified. As Narens (2002:760) notes the association between the concept of meaningfulness and the scale of measurement in the traditional form of representational measurement theory as follows:

A qualitative structure $\boldsymbol{X}$ is selected to capture the domain $\boldsymbol{A}$ of interest; a mathematical representing structure $\boldsymbol{N}$ is selected to measure $\boldsymbol{X}$ in terms of the scale $\boldsymbol{S}$ of homomorphisms of $\boldsymbol{X}$ into $\boldsymbol{N}$; and meaningfulness is identified with a form of invariance associate $\boldsymbol{S}$, e.g. with $\boldsymbol{S}$ - invariance.

This extract indicates that for measurement to take place, it is necessary to specify the qualitative structure of the phenomenon that one intends to measure and the mathematical structure one intends to use to represent the identified phenomenon. From the explanation above it is clear that a scale of measurement explains how an individual has used a mathematical structure to represent an empirical relational structure. It is also evident from this that in the absence of a specified scale of measurement, it would be impossible to know how a mathematical structure has been used to represent an empirical relational structure. It follows that, if a scale of measurement is not specified, it would not be possible to relate the numerical relational structure to the empirical relational structure that it is meant to represent. It is therefore clear from this that if this relationship (scale) cannot be established it will not be possible to draw useful inferences from the representing structure. The explanation above also highlights the need for the scale to be invariant. It is essential that the relationship between an empirical relational structure and a numerical relational structure stay the same. If this relationship was always changing it would be not possible to establish the real and exact relationship between the empirical relational structure and the numerical relational structure. The scale would become ambiguous and, as a result, inferences drawn from the scale would not be meaningful. It follows then that it is also necessary to specify the scales of measurement used in the measurement of accounting phenomena if accounting information is to be considered meaningful. With regard to the absence of a specified attribute of measurement in accounting, this severely compromises the meaningfulness of information. As noted in Section 3 Stevens (1946), associates meaningfulness with invariance under permissible statistics. This means that the statistical analyses that are carried out on a set of measurement data should also be representative of 
the underlying empirical relational structure that the data set represents. This also indicates that the underlying empirical relational structure should be objective. That is, the empirical relational structure should be capable of being empirically verified.

Similarly Narens (2002: 761) states:

$X$ is said to be a structure with meaningful primitives if and only if $x$ is a qualitative structure and each primitive of $X$ is meaningful.

This points out that a phenomenon that is subject to measurement can give rise to meaningful measurements if the phenomenon itself is meaningful. According to Luce and Narens (1994), a qualitative structure and its primitives are meaningful if the qualitative structure has primitives that can be represented by a numerical relational structure: the qualitative structure can only be meaningful if it has attributes that are measurable. It can be inferred from this that the object of measurement can only lead to meaningful measurements if it has properties that are compatible with the principles of the representational theory of measurement. Luce et al., (1971) makes the point that a phenomenon is measurable if it has a qualitative structure that can be specified, and attributes that can be specified and which have empirical identities. In other words, phenomena that lead to meaningful measurements are those that have attributes that are empirically testable.

The IASB (2009) framework for financial reporting asserts that an item that meets the definition of an element of financial statements should be recognized in the financial statements if the item has a cost or value that can be measured with reliability. This point of view indicates that the phenomena that are subject to measurement in accounting are cost or value. It follows that cost or value should be objects that can be objectively determined. It can also be inferred that the statistical analyses carried out on the abstract structures that represent cost or value should leave the cost or the value of an element of the financial statement invariant.

However, cost and value are both subjective concepts. Authors such as Stamp (1981), Willet (1987), Chambers (1997), Staubus (2004) and Musvoto (2008) point out that value is an ambiguous concept and not an intrinsic property of an accounting entity. This suggests that value is not objective and cannot be determined objectively. The concept of cost cannot be determined objectively either because there is no agreement in accounting on what constitutes cost. This is made clear in a definition of cost. The IAS 38 (2009, Para 8) defines cost as follows:

Cost is the amount of cash or cash equivalents paid or the fair value of other consideration given to acquire an asset at the time of its acquisition or construction...

This suggests that cost is used as the value of the measurement function. Yet, cost was earlier (IASB, 2009) referred to as the domain of the measurement function. It was classified as the attribute that is the subject of measurement in accounting. This indicates that the accounting discipline has not fully recognized the distinction between the preformed theoretical constructs of the empirical relational system, the measurement function and the value of the measurement function. The absence of specified empirical relational structures for both cost and value imply that they are not measurable. Since it has been noted above (Luce and Narens, 1994) that meaningful measurements can only be constructed from phenomena that are measurable, it can be concluded that the empirical relational structure of both cost and value do not lead to meaningful measurements.

\section{MEANINGFULNESS AND THE LOGIC OF HYPOTHESIS TESTING}

In Section 3 the point was made (Stevens, 1951, 1946) that the meaningfulness of statements about measurement information for different scale types is preserved under permissible transformations on those scales. This means that when specifying the meaningfulness of measurement information, the scale of measurement used in a process of measurement as well as the permissible statistics for that particular type of scale must also be specified. Once the scale of measurement and permissible statistics on a set of measurement data have been specified it is possible to determine whether a set of measurement data is meaningful. 
However, Stevens' $(1951,1946)$ link between meaningfulness and permissible statistics is controversial. This link fails to take into account the logic of statistical hypothesis testing. Lord (1946) reflected the weakness in Stevens' (1946) work on meaningfulness by showing that the choice of permissible statistical tests for a given set of data does not depend on the representation and uniqueness theorems, but rather that they are dependent on the question they are designed to answer. It can also be inferred that this logic of meaningfulness of measurement data depends on data distributional assumptions: that is, if the data distributional assumptions are true, then the statistical calculations follow and provide firm grounds for inferences. If this logic is applied to accounting measurement it means that the nature of the statistical tests conducted on accounting information should not depend on how monetary amounts represent the values of the elements of financial statements (proving the representation and uniqueness theorem), but rather on whatever the user wants to use the information for.

Guttman (1977) points out that the statistical interpretation of data depends on the questions asked of it and on the kind of evidence that the enquirer would accept to inform him about that question. This means that it is the enquirer who determines what he wants from the information. This suggests that the questions asked of accounting information should be determined by the users of the information and not by the accountants or any other persons involved in the production of accounting information. The users know how they will use this information. They carry out statistical tests on accounting information that reveal whether this information is suitable for the task they want to perform.

\section{CONCLUSIONS}

The concept of meaningfulness is fundamental to every process of measurement. The inability of a process of measurement to establish the meaningfulness of the measurements it produces is a clear demonstration that it is not a process of measurement. Accounting is currently considered to be a measurement discipline. One would therefore expect accounting information to be meaningful. Meaningful statements about measurement information are those that preserve the relationship between the numerical relational structure and the empirical relational structure. Meaningful statements leave the scale of measurement invariant. In this study it has been argued that accounting information is not meaningful.

Despite the fact that the accounting literature suggests that accounting is a measurement discipline, an analysis of accounting measurement information indicates that this information is not meaningful. A recap of some of the main points discussed in this study is provided below:

- $\quad$ The meaningfulness of statements about measurement data is preserved under transformations that are permissible on that data. Permissible transformations are those transformations that leave the scale of measurement used in a process of measurement invariant. A scale of measurement specifies the statistical procedures that may be carried out on measurement information. The concept of meaningfulness is an all or nothing concept. Either a statement is meaningful or it is not.

- $\quad$ The object of measurement in the accounting discipline is value or cost. Monetary units are used to represent the value of the elements of financial statements. This means that in the accounting discipline, meaningful statements about measurement information are those that preserve the relationship between monetary units and value.

- In the accounting discipline there are no specified scales of measurement. Yet measurement information is meaningful once a scale of measurement is specified. Therefore, it is clear that accounting measurement information is currently not meaningful.

- $\quad$ The value of an element of the financial statement is ambiguous. Thus, it follows that the value of such an element cannot be empirically tested. This means that the invariance of value cannot be established when a statistical procedure is performed on measurements of value. It follows from this that the meaningfulness of accounting information cannot be established.

The obvious conclusion that can be drawn from this study is that the numerical assignments made in the accounting discipline cannot be considered to be meaningful. They do not meet the requirements of the principles of the representational theory of measurement that establish meaningfulness. 


\section{RECOMMENDATIONS}

In the light of the findings above, it is recommended that the accounting discipline should be declassified as a measurement discipline until such a time when a theory of meaningfulness of accounting information has been developed in the discipline. Such declassification would inform the users on the nature of reliability that may be placed on the information contained in the financial statements.

\section{AUTHOR INFORMATION}

S Wedzerai Musvoto, Ph.D. is a senior lecturer in Financial Management and Accounting at the School of Accounting Sciences of the North-West University's Vaal Triangle Campus. He received his PhD from the University of Pretoria in 2008. Dr Musvoto is also affiliated with the Association of Chartered Certified Accountants and the Chartered Institute of Management Accountants. His research interests include accounting measurement, risk management and the implications of modern principles of measurement on finance theory development. E-mail: swmusvoto@yahoo.com (Corresponding author)

Professor Daan G. Gouws is a Professor in the Faculty of Economic and Management Sciences of the University of Pretoria in South Africa. Dr Gouws is the author of many refereed papers regarding trans disciplinary research in accounting, finance and educational issues. He is co-editor of various refereed journals and is(was) the supervisor of more than 120 master's and doctoral students. Prof Gouws won in 2000 the national award as the "Most outstanding Accounting and Finance Educator" in South Africa.

\section{BIBLIOGRAPHY}

1. Agoglia, C.P., Doupnik, T.S., Tsakumis, G.T. (2011) Principles -Based Versus Rules based Accounting Standards: The Influence of Standard Precision and Audit Committee Strength on Financial Reporting Decisions, The Accounting Review, Vol 86 (3) : 747-767

2. Chambers, R.J. (1997) "Wanted: Foundations of Accounting Measurement", Abacus, 34(1): 36-47.

3. Evans, T.G. (2003). Accounting Theory: Contemporary Accounting Issues, Thomson, South Western, USA

4. Fellner, W. (1961) "Distortion of Subjective Probabilities as a Reaction to Uncertainty," Quarterly Journal of Economics, Vol 75: 670-689

5. Franke, G., (1978) Expected Utility With Ambiguous Probabilities and Irrational Parameters," Theory and Decision, Vol. 9:267-283

6. Francis, J. \& Schipper, K. (1999) "Have financial statements lost their relevance? Journal of Accounting Research, Autumn, 37(2): 319-351.

7. International Accounting Standards Board (IASB), 2009, International Financial Reporting Standards (IFRS) (2009): Including International Accounting Standards (IAS) and interpretations as at 1 July 2009. Vol 1A, 1B, \& IC London: IASB IAS 38: Intangible Assets

8. Kaplan, R.S (2011) "Accounting Scholarship that Advances Professional Knowledge and Practice", The Accounting Review, Vol 86 (2): 367-383

9. Lev, B. \& Zarowin, P. (1999) "The boundaries of financial reporting and how to extend them" Journal of Accounting Research, Autumn, 37 (2): 353-385

10. Lord, F. (1946). "On the statistical treatment of football numbers" American Psychologist, 8: 750-751.

11. Luce, R, D. \& Narens, L. (1994) "Fifteen Problems Concerning The Representational Theory of Measurement". Available, http:// www. Imbs.uci.edu / personnel / Luce / 1994/ Luce \& Narens Book \% 20 Chapter 1994.pdf, Accessed 2006/10/10

12. Luce, R. D.; Krantz, D.H.; Suppes, P. \& Tversk, A. (1990) Foundations of Measurement, (Vol. 3) Representations, axiomatization, and invariance, New York: Academic Press

13. Luce, R. D.; Krantz, D.H.; Suppes, P. \& Tversk, A. (1989) "Foundations of Measurement" (Vol. 2) Geometrical, threshold, and probabilistic representations", New York: Academic Press

14. Luce, R. D.; Krantz, D.H.; Suppes, P. \& Tversk, A. (1971) "Foundations of Measurement, (Vol. 1) Additive and Polynomial representations", New York: Academic Press

15. Michell, J. (1995). Further Thoughts on Realism, Representationalism, and the Foundations of Measurement Theory, Journal of Mathematical Psychology 39: 243-247. 
16. Musvoto, S.W (2008) "Applying the representational theory of measurement to accounting", $\mathrm{PhD}$ thesis, University of Pretoria, Pretoria, Viewed http://upetd.up.ac.za/thesis/available/etd-03282009-125051/

17. Narens, L. (2002) “A meaningful justification for the representational Theory of Measurement”, Journal of Mathematical Psychology, 46: 746-768

18. Ryan, B.; Scapens, R.W \& Theobald, M. (2002) "Research Method and Methodology in finance and Accounting", Second Edition, Mitcham, Surrey, International, Padstow, Cornwall

19. Stamp, E. (1981), "Why can Accounting not become a Science like Physics?", Abacus, June, 13-27

20. Sterling, R. R. (1997). The quest for a science of accounting: An anthology of the Research of Robert $R$ Sterling, Edited by T.A. Lee and P.W. Wolnizer, Garland Publishing Inc, New York.

21. Stevens, S.S. (1946). On the theory of scales of measurement, Science, 103: 667-680

22. Stevens, S.S. (1951). Mathematics, Measurement and psychophysics, in (Ed), Handbook of Experimental psychology, New York: Wiley.

23. Scott, D. \& Suppes, P. (1958) "Foundational Aspects of Theories of Measurement", Journal of Symbolic Logic, 23, 113-128

24. Staubus, G. J. (2004) "Two views of Accounting Measurement”, Abacus, 40 (3): 265-279

25. Townsend, J.T. \& Ashby, F.G. (1984) Measurement Scales and Statistics: The Misconception Misconceived, Psychological Bulletin, 96(2): 394-401.

26. Vickrey, D. W. (1970). Is Accounting a Measurement Discipline? Accounting Review, 45 (4): 731-742.

27. Willet, R. J. (1987) “An Axiomatic Theory of Accounting measurement”, Accounting and Business Research: 155-171.

28. Wolk, H.I., Tearney, M.G. \& Dodd, J.L. (2001) Accounting Theory: A Conceptual And Institutional Approach. South Western College Publishing

29. Zebda, A. (1991). The problem of ambiguity and vagueness in accounting, Behavioural Research in Accounting, 3, 117-145 
NOTES 